\title{
The relationship between COVID-related parenting stress, nonresponsive feeding behaviors, and parent mental health
}

\author{
Leslie Ann Frankel ${ }^{1}$. Caroline Bena Kuno ${ }^{1} \cdot$ Ritu Sampige $^{1}$ \\ Accepted: 22 September 2021 \\ (c) The Author(s), under exclusive licence to Springer Science+Business Media, LLC, part of Springer Nature 2021
}

\begin{abstract}
COVID-19 has disrupted the lives of families across the United States and all over the world. Stress is known to have a negative impact on parent-child feeding interactions; hence, the purpose of this study is to examine how COVID-related parenting stress, which was measured using a newly developed scale, is related to parent mental health, nonresponsive feeding, and children's self-regulation of eating. 119 parents of children ages 2-7 years old filled out questions about COVID-related parenting stress, mental health, nonresponsive feeding behaviors, and children's self-regulation of eating. A series of multiple regressions were run to predict parent anxiety and psychological distress from COVID-related parenting stress. COVID-related parenting stress was found to be a significant predictor of both parent anxiety and psychological distress. When COVID-related parenting stress was further broken down into COVID-Related Job/Financial Security Stress and COVID-Related Family Safety/Stability Stress, COVID-Related Job/Financial Security Stress predicted psychological distress while COVID-Related Family Safety/Stability Stress predicted parent anxiety. Moderation analyses were also run to test the difference across the parents of children under 5 years of age and those of children who were 5 years of age and older regarding the association of COVID-related parenting stress and either parent anxiety or psychological distress. There was no significant difference across age. Lastly, COVID-related parenting stress and nonresponsive feeding practices were simultaneously entered into a multiple regression to predict children's self-regulation of eating, and COVID-related parenting stress and parent distrust in appetite were both found to decrease children's ability to self-regulate energy intake. Based on findings from this study, researchers interested in improving children's self-regulation of eating and long-term health outcomes should continue to target the reduction of nonresponsive parent feeding behaviors, but they should also aim to look beyond specific parent feeding behaviors by attempting to help parents manage stressors in their lives.
\end{abstract}

Keywords Health behavior · Parenting $\cdot$ Parent psychosocial function · Infancy and early childhood · Self-regulation of eating

Prior literature indicates that parenting stress can lead to both depression and anxiety symptomatology (Rolle et al., 2017). Similarly, the stress related to COVID-19 has also resulted in increases in symptomatology of anxiety and depression (Salari et al., 2020), and the sudden COVID19 lockdown mandate was marked by a significant increase in psychological distress in March-April of 2020 (Daly \& Robinson, 2021). In March of 2020, schools and workplaces across the United States of America shut down as a result

Leslie Ann Frankel

Lafrankel@uh.edu

1 Department of Psychological, Health and Learning Sciences, University of Houston, 491 Farish Hall, Houston, TX 77204, USA of the COVID-19 pandemic, and there has been a significant rise in parenting stress post school-shutdown (Hiraoka $\&$ Tomoda, 2020). Such parenting stress is attributed to pandemic-specific changes to children's childcare, safety, education (Yoshikawa et al., 2020), and family financial stability (Benner \& Mistry, 2020; Prime et al., 2020). Unique stressors that parents have had to face during the COVID-19 pandemic include, but are not limited to, abrupt closures of schools and childcare centers (Petts et al., 2020). Because of this, parents were suddenly left without appropriate childcare options and were immediately required to take on increased responsibilities related to the delivery of their children's education (Lee et al., 2021). To make matters worse, the highly contagious nature and uncertainty around the COVID-19 pandemic forced typical activities that children 
might enjoy, such as going to the playground, extracurricular activities, or afterschool activities, to shut down as well, thus reducing avenues for parents to keep their children engaged and occupied (Cluver et al., 2020). At the same time, parents were also facing pandemic-related economic strain and work-related stressors such as offices shutting down (Petts et al., 2020). Due to the rise of quarantine and social distancing requirements, responsibilities of parents multiplied as they were suddenly required to manage both householdand work-related responsibilities concurrently in a single environment (Petts et al., 2020), and such sudden blending of environments is stress-inducing (Marchetti et al., 2020). To this point, parents reported experiences of higher stress levels if they were working during the pandemic, which may best be explained by the need to juggle multiple roles, such as being a caregiver, educator, and employee, simultaneously (Freisthler et al., 2021). In an attempt to keep their families safe and in response to the U.S. "stay-at-home" orders, many parents were required to engage in various quarantine protocols involving the vast reduction of everyday contacts and drastic changes to their own everyday social activities (Lee et al., 2021), which are further inducers of parental stress during the pandemic (Calvano et al., 2021). In light of social distancing requirements that were catalyzed by the pandemic, parents are overwhelmed, socially isolated, and lack the traditional support systems that they may have had before the pandemic due to the need to protect themselves and their family, including their own children, from exposure to the virus, which contribute to parents' experiences of situational COVID-related parenting stress.

Greater parent stress levels are associated with more unresponsive parenting towards children, which is characterized by parents' struggle and inability to recognize and aptly respond to children's needs (östberg, 1998). In other words, because parents are facing significantly more situational parenting stress after the shutdown of schools (Hiraoka \& Tomoda, 2020), such stress may contribute to strain on the parent-child relationship by placing parents at greater risk for the use of unresponsive parenting behaviors with their children (Benner \& Mistry, 2020), which include the utilization of nonresponsive feeding behaviors. Hughes et al. (2015) posited that the mechanism for this is that parents who are experiencing high levels of stress do not have the time, energy, or emotional capacity to engage in optimal feeding behaviors and instead resort to maladaptive feeding behaviors. From the few studies in the literature around stress and parent feeding, we see an association between parent experiences of stress and their use of nonresponsive feeding behaviors. Parents experiencing high levels of parenting stress engage in the use of food as a reward (Gouveia et al., 2019) and pressure to eat (Berge et al., 2017) which are both nonresponsive feeding practices (Jansen et al., 2014). Given that parents are experiencing unprecedented levels of stress during the COVID-19 pandemic (Prime et al., 2020), we expect that such stress would negatively impact feeding behaviors and children's eating behaviors, which may be represented by their suboptimal ability to self-regulate energy intake.

Parent feeding behaviors have important implications for children's health outcomes, such as weight and the ability to self-regulate eating (Faith et al., 2004; Frankel et al., 2012). "Nonresponsive feeding behaviors" are characterized by parents failing to observe cues or listen to their children's feedback about hunger or fullness during feeding (Lindsay et al., 2017). Distrust in children's appetite, rewards around food, and pressure to eat all fall under the umbrella of nonresponsive feeding behaviors (Jansen et al., 2014). Moreover, nonresponsive parent feeding practices are maladaptive for children's optimal self-regulation of eating. These practices attempt to control the child's intake and behavior during feeding through using the food as a reward or comfort, restricting food intake, and pressuring the child to eat (Daniels et al., 2015). Instead of responding to child cues and communication around hunger and fullness, nonresponsive feeding practices are parental attempts to externally control the child's food intake. Nonresponsive feeding practices therefore override children's ability to understand and respond to their own internal feelings of hunger or fullness (Daniels et al., 2015) and have thus been tied to higher child weight status and obesity in children in two systematic reviews (Faith et al., 2004; Hurley et al., 2011).

Children's self-regulation of eating refers to their ability to respond to internal cues of hunger and fullness when making decisions about consumption (Frankel et al., 2012; Vohs $\&$ Baumeister, 2016). Optimal ability to self-regulate eating is important for children to be of a healthy weight status and to not overeat (Johnson \& Birch, 1994). Frankel et al. (2014) found that parents of obese children rated their children as lower in satiety responsiveness, higher in enjoyment of food, and higher in food responsiveness compared to parents of underweight and healthy weight children, indicating that obese children might have lessened ability to self-regulate eating. Children's ability to self-regulate eating is influenced by environmental factors, including parent feeding practices (Faith et al., 2012). To this point, nonresponsive feeding behaviors have been tied with children's decreased ability to self-regulate energy intake. As an example, researchers have found that the parent control (Johnson \& Birch, 1994) and restriction (Fisher \& Birch, 1999; Fisher \& Birch, 2002) of food is related to children's lessened ability to self-regulate energy intake.

There is a dearth of literature regarding how parent experiences of stress impact children's eating behaviors (Berge et al., 2020). General parent stress has been tied to nonresponsive feeding behaviors. Berge et al. (2017) found that 
parents experiencing high levels of general stress earlier in the day are more likely ( 1.45 odds ratio) to engage in pressure-to-eat feeding practices (form of nonresponsive feeding behavior) at dinner. People reported higher levels of stress during the COVID-19 pandemic than before this pandemic started (American Psychological Association, 2020). Therefore, there is a need to identify a relationship between the nonresponsive feeding behaviors that are observed during times of situational COVID-related parenting stress and children's ability to self-regulate energy intake.

Researchers have recently found that COVID-related stress is associated with personal health-related motivations and behaviors. Specifically, Smith et al. (2021) found that individuals who believe they are under high amounts of COVID-related stress are more motivated to perform a high effort task (in this example, measured by willingness to do jumping jacks) for preferred foods and willing to pay more for such desired foods compared to individuals experiencing lower amounts of COVID-related stress. The authors of this study consider differences in motivations across individuals under high and low amounts of COVID-related stress to imply that COVID-related stress is associated with foodrelated behaviors including food motivation (Smith et al., 2021). It is not clear, however, how COVID-related stress impacts parent feeding. Given these findings regarding COVID and one food-related behavior (motivation) and that general stress impacts parent feeding (Berge et al., 2017), COVID-related stress may also impact parent feeding behaviors. More specifically, parent-child feeding interactions will likely be negatively impacted by COVID-related parenting stress since parent experiences of stress are thought to contribute to their use of maladaptive parent feeding behaviors.

Although it is difficult to measure the unique impact of COVID-related parenting stress, it is important for researchers to do so because stress negatively impacts parenting and parent-child interactions (Neece et al., 2012), and thus COVID-related parenting stress impacts parenting behaviors, which in turn, influence children's health outcomes, such as their eating behaviors and ability to self-regulate eating. Although it is known that parents who experience high levels of stress engage in nonresponsive feeding behaviors, it is not clear how the unique situational stress that parents experience during the pandemic impacts parent mental health, feeding behaviors, or children's ability to selfregulate energy intake due to parents' feeding behaviors. As a result, the goal of this study is to validate a novel selfreport measure of COVID-related parenting stress and to examine its relation to parent mental health, nonresponsive feeding, and children's self-regulation of eating. Because of the unique stressors that are brought about specifically by the pandemic, there is a need to chart the current unprecedented, situational COVID-related parenting stress that parents are experiencing with a measure that is specific to the uncharted stressors that have occurred solely in this COVID-19 timepoint.

Furthermore, due to the interconnected nature between parent stress, parents' ensuing inclination towards nonresponsive feeding behaviors, and children's resulting risk for suboptimal self-regulation of eating, this study will examine the relationship between parent stress caused by COVID-19, parents' utilization of nonresponsive feeding behaviors, and children's subsequent ability to self-regulate energy intake. Thus, our hypotheses are as follows: 1) parents experiencing higher levels of COVID-related parenting stress will also self-report higher levels of mental health symptomatology that include anxiety and psychological distress 2) parents' COVID-related stress and use of nonresponsive feeding behaviors will predict children's lessened ability to selfregulate eating.

\section{Methods}

Participants were recruited for this study via Facebook posts and targeted advertisements on Facebook and Instagram to parents (above the age of 18) of young children. Participants in this study completed a self-report survey after consenting between the periods of mid-April to early June of 2020 in Qualtrics, a secure online data collection software. Upon completing the survey, parents had an opportunity to enter into a drawing for an Amazon Echo Dot. This study was approved by the Institutional Review Board at The University of Houston.

\section{Data}

The sample consisted of 147 parents who consented and answered at least one question in the survey. Of the 147 that consented, 119 responded to at least one question related to COVID-19. This study therefore utilized a sample size of 119 . The mean age for the parents was 36.26 years with a standard deviation of 4.43 , and that of the children was 4.50 years with a standard deviation of 1.58 . A majority of the parents stated that their race is White (51.3\%), followed by Asian (5.9\%), and Black or African American (0.8\%). $42 \%$ of parents did not state their race (missing, see Table 1 ).

\section{Measures}

Outcomes Anxiety was measured with the six-item shortform of the State-Trait Anxiety Inventory (STAI), which includes like "I am worried," from (STAI), a reliable questionnaire to quantify anxiety. Participants responded to a 4-point Likert scale questionnaire, ranging from 1, "Not at all" to 4, "Very much." There were two subscales of the questionnaire, which were "anxiety absent" and "anxiety 
Table 1 Demographics of Sample $(\mathrm{n}=119)$

\begin{tabular}{|c|c|}
\hline Variable description & $\mathrm{N}(\%)$ or Mean $\pm \mathrm{SD}$ \\
\hline \multicolumn{2}{|l|}{ Child's gender } \\
\hline Male & $64(53.80)$ \\
\hline Female & $55(46.20)$ \\
\hline Child age & $4.50 \pm 1.58$ \\
\hline Child self-regulation in eating Child self-regulation in eating & $3.90 \pm 0.74$ \\
\hline \multicolumn{2}{|l|}{ Parent's gender } \\
\hline Male & $4(3.40)$ \\
\hline Female & $64(53.80)$ \\
\hline Missing & $51(42.90)$ \\
\hline Parent's age & $36.26 \pm 4.43$ \\
\hline \multicolumn{2}{|l|}{ Parent's educational level } \\
\hline High school graduate (high school diploma or equivalent including GED) & $1(0.80)$ \\
\hline Some college but no degree & $6(5.00)$ \\
\hline Associate degree in college (2-year) & $3(2.50)$ \\
\hline Bachelor's degree in college (4-year) & $23(19.30)$ \\
\hline Master's degree & $18(15.10)$ \\
\hline Doctoral degree & $15(12.60)$ \\
\hline Professional degree (JD, MD) & $3(2.50)$ \\
\hline Missing & $50(42.00)$ \\
\hline \multicolumn{2}{|l|}{ Parent's income level } \\
\hline Less than $\$ 15,000$ & $3(2.50)$ \\
\hline$\$ 25,001-\$ 49,999$ & $7(5.90)$ \\
\hline$\$ 50,000-\$ 74,999$ & $7(5.90)$ \\
\hline$\$ 75,000-\$ 99,999$ & $6(5.00)$ \\
\hline$\$ 100,000-\$ 149,999$ & $19(16.00)$ \\
\hline$\$ 150,000$ and over & $27(22.70)$ \\
\hline Missing & $50(42.00)$ \\
\hline \multicolumn{2}{|l|}{ Parent's race } \\
\hline White & $61(51.30)$ \\
\hline Black or African American & $1(0.80)$ \\
\hline Asian & $7(5.90)$ \\
\hline Missing & $50(42.00)$ \\
\hline COVID-Related Parenting Stress Scale & $24.99 \pm 6.29$ \\
\hline COVID-Related Job/Financial Security Stress & $7.36 \pm 2.89$ \\
\hline COVID-Related Family Safety/Stability Stress & $17.63 \pm 4.83$ \\
\hline Anxiety & $2.13 \pm 0.75$ \\
\hline Psychological Distress & $3.76 \pm 2.89$ \\
\hline \multicolumn{2}{|l|}{ Parental Feeding Practices } \\
\hline Distrust in Appetite & $2.70 \pm 0.79$ \\
\hline Reward for Behavior & $2.24 \pm 0.87$ \\
\hline Reward for Eating & $2.35 \pm 0.82$ \\
\hline Persuasive Feeding & $2.99 \pm 0.73$ \\
\hline
\end{tabular}

present" (Marteau \& Bekker, 1992). The 3-item anxiety present scale was used for these analyses and had a high Cronbach's alpha in this sample $(\alpha=0.80)$.

Psychological distress was measured using the 4-item Patient Health Questionnaire (PHQ-4) for Depression and Anxiety. The items had a relatively high Cronbach's alpha of 0.82 in this sample of participants. Participants responded to a 4-point Likert scale questionnaire ranging from 0 , "Not at all" to 3 , "Nearly every day." There were two subscales in the PHQ- 4 , which were the anxiety subscale and the depression subscale, thus allowing for a rapid measurement of both mental health disorders. From the original paper, the scale had a high Cronbach's alpha $(\alpha=0.85)$ and construct validity was established (Kroenke et al., 2009). 
The eight-item Self-Regulation in Eating Scale by Tan and Holub (Tan \& Holub, 2011) was used to measure parent perception of children's ability to self-regulate eating. Parents responded to the 8-item scale containing items such as, "My child knows when s/he is full." The scale consisted of a 5-point Likert scale, with a high score of 5, "agree," and low score of 1, "disagree." Scores were averaged, and higher scores indicated higher self-regulation in eating. A high Cronbach's alpha was reported in the original validation paper $(\alpha=0.87)$ (Tan \& Holub, 2011) and was $\alpha=0.81$ in this sample.

\section{Predictors}

The COVID-Related Parenting Stress Scale is a novel scale created by two of this paper's authors (RS and LF) to examine the extent of how unique aspects of COVID-19 impacted ability to parent. There are two subscales-the 8 -item subscale regarding COVID-Related Family Safety/Stability Stress (ex: "How confident are you in your ability to keep your child educated during this COVID-19 situation?") and a 3-item subscale regarding COVID-Related Job/Financial Security Stress (ex: "To what extent do you feel you or your family's financial stability is at risk?") (Online Resource 2). For this scale, participants responded to a 5-point Likert scale questionnaire, ranging from 1, "Extremely" to 5, "Not at all". The COVID-Related Job/Financial Security Stress had an acceptable Cronbach's alpha of 0.62 while the 8 -item subscale regarding COVID-Related Family Safety/Stability Stress had a good Cronbach's alpha of 0.81. All 11 items together had a good Cronbach's alpha of 0.80 (George \& Mallery, 2003; Hair et al., 2010).

The following scales of Distrust in Appetite, Reward for Behavior, Reward for Eating, and Persuasive Feeding that measure nonresponsive feeding were used to predict self-regulation in eating. The scales were obtained from the Feeding Practices and Structure Questionnaire, a questionnaire where parents report their practices around feeding, including Distrust in Appetite, Reward for Behavior, Reward for Eating, and Persuasive Feeding. Distrust in Appetite (parents' lack of trust with children's self-assessment and expression of hunger or fullness) was measured with 4 items; Reward for Behavior (parents utilizing food as a reward for children's good behavior or to get the child to behave the way they want them to) was measured with 6 items; Reward for Eating (parents providing desired food or promise as a reward or removing an undesired food item if necessary foods/meal are first consumed) was measured with 6 items; Persuasive Feeding (parents convincing children to continue eating or showing disapproval for not eating) was measured with 5 items. Participants responded to a 5-point Likert scale questionnaire ranging from 1, "Never" to 5, "Always" for each scale. The original validation paper reported acceptable Cronbach's alphas for Distrust in Appetite $(\alpha=0.63)$, Reward for Behavior $(\alpha=0.86)$, Reward for Eating $(\alpha=0.89)$ and Persuasive Feeding $(\alpha=0.73)$. The scores for the items in each scale were averaged and used in the analysis. These four scales, which represent nonresponsive feeding behaviors, were found to be highly correlated in the original validation paper $(r=0.86)$ (Jansen et al., 2014).

Control variables included parent education level, income level, and gender of the parent.

\section{Statistical Analysis}

The analysis was carried out in both SPSS 25 and MPLUS 8 (Muthén \& Muthén, 2017). First, a frequency distribution of all the variables was obtained for a visual observation of any data abnormalities, such as outliers and missing values. A box plot was then used to identify any values considered to be outliers. There was no evidence of outliers. There were missing data in 5 variables of the analysis; gender of the parent had the highest missing data percentage (43\%), followed by income level (42\%) and educational level (42\%). There were no missing data on the COVID-related constructs. The rest of the missing data pattern is shown in the demographic Table 1. The Kruskal Wallis test for continuous variables and the Chi-Squared test for categorical variables did not fully support the assumption that data were missing completely at random (MCAR) for some variables in the analysis. Also, due to the confidential nature (i.e., non-disclosure identifying information of the participants) of the study, there is lack of evidence to support that the missing data mechanism was missing not at random (MNAR). Based on the reasoning above, the data were assumed to be missing at random (MAR). Data are missing at random when the probability of missingness of values of a specific variable depends only on the available information (Gelman \& Hill, 2006). In other words, this is when the probability that a value is missing for a variable is related to the other variables in the dataset. A multiple imputation with 50 datasets for all the variables involved in the analysis was performed in MPLUS to handle missing values during the multiple regression analyses. All categorical variables were dummy coded. Second, internal consistency and exploratory factor analysis were performed to test the reliability and construct validity of the COVID-Related Parenting Stress Scale. Finally, to test hypothesis 1 , four multiple regression models were fit to the data to predict parent anxiety and psychological distress from COVID-related parenting stress. To test hypothesis 2 , a fifth multiple regression was fit to the data to predict children's self-regulation in eating from COVID-related parenting stress and nonresponsive feeding behaviors. All of the predictor variables were entered simultaneously into the model controlling for each other's effects. Level of education 
of the parent was coded as associate degree and below $=1$, bachelor's degree and above $=0$; income level of the parent was coded as $\$ 49,999$ and below $=1,50,000$ and above $=0$; gender of the parent was coded as female $=1$, male $=0$. These three variables were the control variables in all of the regressions. Finally, moderation analyses (interaction terms between a child's age group and COVID-related parenting stress) for all of the models were performed to test the difference between parents of children under 5 years of age and those of children who were 5 years of age and older regarding the association between COVID-related parenting stress and parent anxiety, psychological distress, and children's self-regulation in eating. Children under 5 years of age were dummy coded as 1 while those who were 5 years and older were dummy coded as 0 .

\section{Results}

The novel scale measures the severity of COVID-related parenting stress. Although everyone is affected by COVID19 , the extent of the impact varies based on each individual's situation, thus warranting a scale that measures the level of impact on parenting due to COVID-19.

\section{Reliability and Exploratory Factor Analysis (EFA)}

Exploratory factor analysis was conducted to examine if the items were good indicators of the intended construct (COVID-Related Parenting Stress Scale). A preliminary exploratory factor analysis indicated 3 items to have poor factor loadings. These items were then excluded from the preceding exploratory factor analysis that had one factor. The factor loadings from this analysis ranged from low (0.20) to relatively high (0.77). Another exploratory factor analysis was conducted with two factors, one factor was related to job/financial security and the second factor was related to family safety/stability. The factor loadings for both of the subscales ranged from moderate $(0.45-0.59)$ to relatively high (0.73), suggesting that the items were relatively good indicators of the subscales. Factor 1 (family safety/ stability) explained about 29.70 variance while factor 2 (job/ financial security) explained about 9.04 variance. Additionally, Cronbach's alphas for all of the items in the COVIDRelated Parenting Stress Scale were good $(\alpha=0.80)$, indicating good internal consistency of the items in the scale. A 3-item subscale of COVID-Related Job/Financial Security Stress had an acceptable Cronbach's alpha of 0.62 while the 8-item subscale regarding COVID-Related Family Safety/ Stability Stress had a good Cronbach's alpha of 0.81 (George \& Mallery, 2003; Hair et al., 2010). Table 2 details more information from the factor loading matrix of the exploratory factor analysis.

\section{Multiple Regressions}

\section{Addressing Hypothesis 1}

Four multiple regression models were conducted to predict parenting anxiety and psychological distress from COVIDrelated parenting stress while controlling for income level, education level, parent gender, and income change due to COVID-19 (Online Resource 1). All four models were statistically significant. Given that the main predictors

Table 2 Factor Loading Matrix From the Exploratory Factor Analysis of the COVID-Related Parenting Stress Scale $(\mathrm{n}=119)$

\begin{tabular}{lcc}
\hline & Factor loadings \\
\cline { 2 - 2 } Measures & $\begin{array}{c}\text { Family stress } \\
\text { Job/Finan- } \\
\text { cial Stress }\end{array}$ \\
\hline How confident are you in your ability to keep your child healthy during this COVID-19 situation? & 0.731 & 0.112 \\
How confident are you in in your ability to keep your child safe during this COVID-19 situation? & 0.644 & 0.606 \\
How confident are you in your ability to access other household items? & 0.593 & 0.028 \\
How confident are you/your family in following the quarantine/social isolation protocols? & 0.553 \\
How confident are you in your ability to access healthy food? & 0.529 \\
How confident are you in your ability to access food? & 0.500 \\
How confident are you in your ability to keep your child occupied during this COVID-19 situation? & 0.494 \\
How confident are you in your ability to keep your child educated during this COVID-19 situation? & -0.130 \\
(R) To what extent has your work situation changed as a result of the COVID-19 situation? & 0.155 \\
(R) To what extent do you feel you or your family's financial stability is at risk? & 0.308 \\
How confident are you in your ability to maintain your job during this COVID-19 situation? & 0.236 \\
& 0.304 & 0.259 \\
\hline
\end{tabular}

(R) denotes reversed coding 
(COVID-related parenting stress variables) of interest were not tested multiple times, significance level $(\alpha=0.05$ or 0.01 ) were not adjusted for type 1 error using a Bonferronitype adjustment (Mundfrom et al., 2006).

For model 1 (see Table 3), about 19\% of the overall variance was explained by the four predictors in the model. COVID-related parenting stress (COVID) was statistically significant and positively related to anxiety $(\beta=0.035$, $p<0.01)$. The results indicate that a one unit increase in COVID-related parenting stress is expected to increase anxiety by 0.035 after controlling for education level of the parent, income level of the parent, and gender of the parent. Additionally, parent's gender was statistically significant and positively related to anxiety $(\beta=0.729, p<0.05)$. The results indicated that a female parent, compared to a male parent, is expected to increase anxiety by 0.729 after controlling for COVID-related parenting stress, education level of the parent, and income level of the parent.

In model 2 (see Table 3), about $21 \%$ of the overall variance was explained by the six predictors in the model. Job/ financial security stress (COVID1) was statistically significant and positively related to anxiety $(\beta=0.062, p<0.05)$. The results indicate that a one unit increase in job/financial security stress is expected to increase anxiety by 0.062 after controlling for relatedness to family safety/stability stress, education level of the parent, income level of the parent, and gender of the parent. Additionally, the parent's gender was statistically significant and positively related to anxiety $(\beta=0.788, p<0.05)$. The results indicated that a female parent, compared to a male parent, is expected to increase anxiety by 0.788 after controlling for relatedness to job/ financial security stress, relatedness to family safety/stability stress, education level of the parent, income level of the parent, and gender of the parent.

For model 3 (see Table 3 ), about $22 \%$ of the overall variance was explained by the four predictors in the model. COVID-related parenting stress (COVID) was statistically significant and positively related to psychological distress $(\beta=0.156, p<0.01)$. The results indicate that a one unit increase in COVID-related parenting stress is expected to increase psychological distress (PHQ-4) by 0.156 after controlling for education level of the parent, income level of the parent, and gender of the parent.

In model 4 (see Table 3), about $23 \%$ of the overall variance was explained by the six predictors in the model. Family safety/stability stress (COVID2) was statistically significant and positively related to psychological distress $(\beta=0.144, p<0.05)$. The results indicate that a one unit increase in relatedness to family safety/stability stress is expected to increase psychological distress by 0.144 after controlling for job/financial security stress, education level of the parent, income level of the parent, and gender of the parent. Lastly, moderation analyses (interaction terms between a child's age group and COVID-related parenting stress) were performed to test the difference between the parents of children under 5 years of age and those of children who were 5 years of age and older regarding the association of COVID-related parenting stress and either parent anxiety or psychological distress. There was no significant difference between parent of children under 5 years of age
Table 3 Anxiety and Psychological Distress as Dependent Variables $(n=119)$

\begin{tabular}{|c|c|c|c|c|c|c|c|c|}
\hline \multicolumn{5}{|l|}{ Model 1} & \multicolumn{4}{|l|}{ Model 2} \\
\hline & $\beta$ & SE & $\beta /$ S.E & P-value & $\beta$ & SE & $\beta / \mathrm{S} . \mathrm{E}$ & P-value \\
\hline COVID & 0.035 & 0.012 & 2.808 & 0.005 & & & & \\
\hline Job/Financial Stress & & & & & 0.062 & 0.029 & 2.172 & 0.030 \\
\hline Family Stress & & & & & 0.022 & 0.016 & 1.380 & 0.168 \\
\hline Education level & 0.500 & 0.291 & 1.717 & 0.091 & 0.513 & 0.269 & 1.903 & 0.057 \\
\hline Income level & -0.216 & 0.289 & -0.747 & 0.455 & -0.159 & 0.293 & -0.541 & 0.588 \\
\hline Gender & 0.729 & 0.369 & 1.975 & 0.048 & 0.788 & 0.374 & 2.105 & 0.035 \\
\hline $\mathrm{R}$ squared & 0.192 & & & & 0.205 & & & \\
\hline \multirow[t]{2}{*}{ Model 3} & & & & & Model 4 & & & \\
\hline & $\beta$ & SE & $\beta /$ S.E & P-value & $\beta$ & SE & $\beta / \mathrm{S} . \mathrm{E}$ & P-value \\
\hline COVID & 0.156 & 0.046 & 3.370 & 0.001 & & & & \\
\hline Job/Financial Stress & & & & & 0.183 & 0.107 & 1.713 & 0.087 \\
\hline Family Stress & & & & & 0.144 & 0.063 & 2.293 & 0.022 \\
\hline Education level & 0.519 & 0.273 & 1.903 & 0.057 & 2.125 & 1.105 & 1.923 & 0.054 \\
\hline Income level & -0.284 & 1.114 & -0.255 & 0.799 & -0.159 & 0.293 & -0.541 & 0.588 \\
\hline Gender & 2.428 & 1.277 & 1.902 & 0.057 & 2.489 & 1.300 & 1.915 & 0.056 \\
\hline $\mathrm{R}$ squared & 0.224 & & & & 0.227 & & & \\
\hline
\end{tabular}

Dependent variable: Anxiety (model 1 and model 2) and Psychological Distress (model 3 and model 4). Significant at .05 , S.E $(\beta)=$ standard error 
and those of children who were 5 years and older regarding the association between COVID-related parenting stress and either parenting anxiety $(\beta=0.003, p=0.923)$ or psychological distress $(\beta=0.106, p=0.255)$ after controlling for other variables in the model.

\section{Addressing Hypothesis 2}

To examine the relationship between COVID-related parenting stress, nonresponsive parent feeding practices, and children's ability to self-regulate energy intake, a fifth multiple regression (Table 4) was conducted with eight predictors (COVID-related parenting stress, Distrust in Appetite, Reward for Behavior, Reward for Eating, Persuasive Feeding, parent gender, income, and education level) that were simultaneously entered to predict self-regulation in eating. The model was statistically significant. $32.8 \%$ of the overall variance was explained by the eight predictors in the model. COVID-related parenting stress (COVID) was statistically significant and negatively related to self-regulation in eating $(\beta=-0.022, p<0.05)$. The results indicate that a one unit increase in COVID-related parenting stress is expected to decrease self-regulation in eating by 0.022 after controlling for all the other variables in the model. Additionally, Distrust in Appetite was statistically significant and negatively related to anxiety $(\beta=-0.344, p<0.05)$. The results indicate that a one unit increase in Distrust in Appetite is expected to decrease self-regulation in eating by 0.344 after controlling for all other variables in the model. Finally, education level was statistically significant and positively related to self-regulation in eating $(\beta=0.572, p<0.05)$. The results suggest that having an associate degree or lower, compared to having a bachelor's degree or higher, was more likely to increase children's self-regulation in eating. Lastly, moderation analyses (interaction between a child's age group and COVID-related parenting stress) were performed to test the difference between the parents of children under 5 years of

Table 4 Children's Self-Regulation in Eating as a Dependent Variable

\begin{tabular}{lllll}
\hline Predictors & $\beta$ & SE & $\beta /$ S.E & $P$-value \\
\hline COVID & -0.022 & 0.011 & -1.989 & 0.047 \\
Distrust in Appetite & -0.344 & 0.125 & -2.756 & 0.006 \\
Reward for Behavior & 0.109 & 0.100 & 1.084 & 0.278 \\
Reward for Eating & -0.137 & 0.138 & -0.997 & 0.319 \\
Persuasive Feeding & -0.029 & 0.157 & -0.183 & 0.854 \\
Education level & 0.572 & 0.228 & 2.512 & 0.012 \\
Income level & -0.387 & 0.268 & -1.441 & 0.150 \\
Gender & 0.280 & 0.371 & 0.754 & 0.451 \\
R squared & 0.328 & & & \\
\hline
\end{tabular}

Dependent Variable: Self-regulation in eating. Significant at .05 and .01 , S.E $(\beta)=$ standard error age and those of children who were 5 years of age and older regarding the association between COVID-related parenting stress and children's self-regulation in eating. There was no significant difference between parents of children under 5 years of age and those of children 5 years and older regarding the relationship between COVID-related parenting stress and a child's ability to regulate energy intake $(\beta=0.026$, $p=0.289$ ) after controlling for other variables in the model.

\section{Discussion}

Due to the sudden, unexpected, and rapid spread of COVID19 , families across the nation had to make numerous changes to their lifestyles in response to the national shutdown and social distancing guidelines (Gruber et al., 2021). Parents were confronted with unique COVID-19-specific stressors such as the closure of children's schools and extracurricular activities, shutdown of workplaces, possible layoffs, social isolation, and risk to the family's health, which are sources of pandemic-specific stress for parents (Calvano et al., 2021; Cluver et al., 2020; Dias et al., 2020; Lee et al., 2021; Petts et al., 2020). Because of these unique stressors, there was a pressing need to identify the effects of COVID-Related Parenting Stress on families, including parent mental health and children's ability to self-regulate energy intake. While prior literature has documented the effects of general parenting stress on parent mental health (Rolle et al., 2017) and children's ability to self-regulate energy intake (Berge et al., 2017; Johnson \& Birch, 1994; Fisher \& Birch, 1999; Fisher $\&$ Birch, 2002), there was a need to account for the unique situational stress that parents were experiencing specifically during the COVID-19 pandemic. Hence, the objectives for this study were to determine whether COVID-Related Parenting Stress was associated with increased parent anxiety and psychological distress and to determine whether parents' experiences of COVID-Related Parenting Stress as well as their use of nonresponsive feeding behaviors predicted children's ability to self-regulate energy intake.

In support of hypothesis 1, we found a relationship between parents experiencing COVID-related parenting stress and anxiety (model 1). When we examined two different types of COVID-related parenting stress (COVIDRelated Job/Financial Security Stress and COVID-Related Family Safety/Stability Stress) (model 2), we found that COVID-Related Job/Financial Security Stress was related to anxiety. In models 1 and 2, parent gender was found to be a significant control variable in the regression, which indicates that mothers, compared to fathers, experience a greater increase in anxiety symptomatology while controlling for all other variables in the model. To this point, McLean and Anderson (2009) found in their review that women report greater risk for anxiety disorders compared to 
men, thus underscoring that gender differences in the development of anxiety disorders may play a role in the results we obtained between mothers and fathers. COVID-related parenting stress was also related to psychological distress (model 3). When we examined the two different types of COVID-related parenting stress (model 4) (COVID-Related Job/Financial Security Stress and Related Family Safety/ Stability Stress), we found that COVID-Related Family Safety/Stability Stress was related to psychological distress after controlling for COVID-Related Job/Financial Security Stress, education level of the parent, income level of the parent, and gender of the parent.

The results of the fifth multiple regression partially supported hypothesis 2 (Table 3 ). COVID-related parenting stress and Distrust in Appetite were both found to decrease the ability to self-regulate energy intake, but parental Distrust in Appetite $(\beta=-0.344, p<0.05)$ is more related to self-regulation of energy intake than COVID-related parenting stress (COVID) $(\beta=-0.022, p<0.05)$ based on the standardized coefficients. Education was a positive predictor $(\beta=0.572, p<0.05)$ in this model, suggesting higher self-regulation in eating for children whose parents had an associate degree or lower compared to a bachelor's degree or higher.

Nonresponsive feeding behaviors, including Distrust in Appetite, Reward for Behavior, Reward for Eating, and Persuasive Feeding, were examined in this study (Jansen et al., 2014). Nonresponsive feeding behaviors are thought to be counterproductive to the development of optimal self-regulation of energy intake because they lead children to eat in response to factors outside of their own internal feelings of hunger and fullness (Black \& Aboud, 2011; Daniels, 2019).

Daniels et al. (2015) demonstrated through NOURISH, a randomized controlled trial of parent education around feeding and healthy eating, that parents can be taught to use less nonresponsive feeding strategies with their children and to engage in more responsive feeding behaviors even over three years later (Daniels et al., 2015). Given the link between nonresponsive feeding practices, children's self-regulation, and obesity, the interventions have aimed to reduce nonresponsive feeding practices. Because interventions were effective in the reduction of nonresponsive feeding behaviors before COVID-19, they are likely still effective now and should be investigated as a way to reduce nonresponsive feeding strategies. The current study also points to the management of parent feeding behaviors, especially during experiences of parenting stress, as a potential area to explore interventions seeking to decrease parents' use of nonresponsive feeding behaviors, which may thus reduce the negative impact of nonresponsive feeding behaviors on children's ability to self-regulate energy intake. Findings from this study also indicate that researchers interested in improving children's self-regulation of eating and long-term health outcomes should not just attempt to help parents with specific feeding behaviors but should attempt to help parents more broadly address stressors in their lives because such stressors coupled with feeding behaviors may impact children's eating behaviors and long-term health outcomes. Managing parent stress may improve children's eating outcomes and is a new potential area for researchers and clinicians to explore.

Responsive feeding assumes that parents are able to respond appropriately to children's cues within feeding interactions. According to Black and Aboud (2011), responsive feeding includes in-the-moment responses to children's emotions during feeding in emotionally supportive, well-timed, appropriate ways. This level of sensitive and responsive engagement from parents will, in theory, be threatened any time parents are experiencing high levels of stress.

In the current study, COVID-Related Parenting Stress was significantly and positively related to both anxiety and psychological distress. It is likely that anxiety and psychological distress are related to the sudden, unprecedented changes to parents' lifestyles as a result of the COVID-19 pandemic. The unexpected reduction in childcare resources, school closures, workplace closures as well as the threat to family health are all sources of COVID-Related Parenting Stress (Petts et al., 2020; Yoshikawa et al., 2020), which is significantly associated with parent anxiety and psychological distress. When COVID-Related Parenting Stress was further divided into two subscales, the results indicated that COVID-Related Job/Financial Security Stress was significantly and positively related to anxiety while COVIDRelated Family Safety/Stability Stress was significantly and positively related to psychological distress. This indicates that parental stress around maintaining employment in times of mass layoffs (Dias et al., 2020) and workplace closures (Petts et al., 2020) is associated with anxiety. On the other hand, parents' stress with keeping their family safe and healthy as well as keeping children educated and occupied, especially in light of school and extracurricular activity closures, is associated with psychological distress.

Of the examined nonresponsive feeding behaviors, Distrust in Appetite was significantly and negatively related to children's self-regulation of eating. This is in line with the current literature that shows a significant, negative relationship between nonresponsive feeding behaviors and children's ability to self-regulate energy intake (Dev et al., 2017). When parents utilize nonresponsive feeding behaviors, meaning that parents are not paying attention to or acknowledging children's internal cues of hunger and fullness, parents do not reinforce children's innate ability to self-regulate how much food they are eating based on their own internal cues of hunger and satiety (Dev et al., 2017). Furthermore, in this study, COVID-Related Parenting Stress was significantly and negatively related to children's self-regulation of 
eating. This aligns with the current research that shows that parent stress is related to their use of nonresponsive feeding behaviors (Hurley et al., 2008), which is thus related to children's lower ability to self-regulate energy intake. Lastly, parent education level was significantly related to children's self-regulation of eating such that parents with an associate degree or below had a higher chance of having a child with higher self-regulation of eating. This is contrary to what we would have hypothesized based on current literature. This finding might be due to the impact of the COVID-19 pandemic on families, the sample size of our study, and the variables we controlled for in this study.

\section{Limitations and Future Directions}

Participants self-selected to be in this study. Therefore, selection bias is a concern and impacts the generalizability of the study. This is a common issue with online surveys (Bethlehem, 2010). Another limitation of this study is that a large percentage of the parents did not fill out questions pertaining to their demographic information. The likely reason for this is the layout of the survey because questions regarding demographic data appeared at the end of the survey. Therefore, significant controls in the regressions should be interpreted with caution. Due to sample size limitations, we were not able to look at mediation models to see if nonresponsive feeding behaviors mediate the relationship between COVID-19 related parenting stress and children's self-regulation of eating. This is particularly interesting and would be an important detail for future researchers to analyze, as previous studies have found that parents engage in less responsive and less effective general parenting behaviors (Conger $\&$ Elder, 1994) when they are experiencing stress (Benner $\&$ Mistry, 2020). One counterintuitive result around study controls was found with education; parents having an associate degree or lower were actually associated with children's higher self-regulation in eating. This result may have to do with the simultaneous inclusion of variables in the model or with the small number of people who reported their education level (among other demographic data) in the survey.

Another limitation is the cross-sectional nature of this study. Future researchers should longitudinally examine stressors to see how they interact with nonresponsive parent feeding behaviors over time to better understand how they contribute to children's lessened ability to self-regulate energy intake. Additionally, it would be ideal to look at the links between nonresponsive feeding and parent experiences of stress (in this case, COVID-related parenting stress) through observational research, which can capture the intricacies of how parents respond to children in a moment-bymoment interaction rather than by survey responses.
Supplementary Information The online version contains supplementary material available at https://doi.org/10.1007/s12144-021-02333-y.

Funding Funding for this research was provided by the University of Houston Provost's 50-in-5 award.

Data Availability The authors will provide all data that was used for this review upon request.

Code Availability Not applicable.

\section{Declarations}

The views and opinions in this article are those of the authors and do not of the University of Houston.

Ethics Approval This study was approved by the Institutional Review Board at the University of Houston.

Consent to Participate Informed consent was obtained from all individual participants included in the study.

Consent for Publication Not applicable.

Conflict of Interest The authors report no conflicts of interest and the study was reviewed by the University of Houston Committee for the Protection of Human Subjects.

\section{References}

American Psychological Association (2020). Stress in the time of COVID-19, volume one. https://www.apa.org/news/press/relea ses/stress/2020/stress-in-america-covid.pdf

Benner, A. D., \& Mistry, R. S. (2020). Child development during the COVID-19 pandemic through a life course theory lens. Child Development Perspectives, 14(4), 236-243.

Berge, J. M., Tate, A., Trofholz, A., Fertig, A. R., Miner, M., Crow, S., \& Neumark-Sztainer, D. (2017). Momentary parental stress and food-related parenting practices. Pediatrics, 140(6), e20172295.

Berge, J. M., Fertig, A. R., Trofholz, A., Neumark-Sztainer, D., Rogers, E., \& Loth, K. (2020). Associations between parental stress, parent feeding practices, and child eating behaviors within the context of food insecurity. Preventive Medicine Reports, 19, 101146.

Bethlehem, J. (2010). Selection bias in web surveys. International Statistical Review, 78(2), 161-188.

Black, M. M., \& Aboud, F. E. (2011). Responsive Feeding Is Embedded in a Theoretical Framework of Responsive Parenting. The Journal of Nutrition, 141(3), 490-494. https://doi.org/10.3945/ jn. 110.129973

Calvano, C., Engelke, L., Di Bella, J., Kindermann, J., Renneberg, B., \& Winter, S. M. (2021). Families in the COVID-19 pandemic: Parental stress, parent mental health and the occurrence of adverse childhood experiences-results of a representative survey in Germany. European Child \& Adolescent Psychiatry. https://doi.org/10.1007/s00787-021-01739-0

Conger, R. D., \& Elder, G. H. (1994). Families in troubled times: Adapting to change in rural America (Social Institutions \& Social Change). Aldine de Gruyter.

Cluver, L., Lachman, J. M., Sherr, L., Wessels, I., Krug, E., Rakotomalala, S., Blight, S., Hillis, S., Bachman, G., \& Green, O. J. L. (2020). Parenting in a time of COVID-19. Lancet, 395(10231).

Daly, M., \& Robinson, E. (2021). Psychological distress and adaptation to the COVID-19 crisis in the United States. Journal of 
Psychiatric Research, 136, 603-609. https://doi.org/10.1016/j. jpsychires.2020.10.035

Daniels, L. A. (2019). Feeding practices and parenting: A pathway to child health and family happiness. Annals of Nutrition and Metabolism, 74(2), 29-42.

Daniels, L. A., Mallan, K. M., Nicholson, J. M., Thorpe, K., Nambiar, S., Mauch, C. E., \& Magarey, A. (2015). An Early Feeding Practices Intervention for Obesity Prevention. Pediatrics, 136(1), e40. https://doi.org/10.1542/peds.2014-4108

Dev, D. A., Speirs, K. E., Williams, N. A., Ramsay, S., McBride, B. A., \& Hatton-Bowers, H. (2017). Providers perspectives on self-regulation impact their use of responsive feeding practices in child care. Appetite, 118, 66-74. https://doi.org/10.1016/j. appet.2017.07.022

Dias, F. A., Chance, J., \& Buchanan, A. (2020). The motherhood penalty and The fatherhood premium in employment during covid-19: evidence from The united states. Research in Social Stratification and Mobility, 69, 100542. https://doi.org/10. 1016/j.rssm.2020.100542

Faith, M. S., Scanlon, K. S., Birch, L. L., Francis, L. A., \& Sherry, B. (2004). Parent-Child Feeding Strategies and Their Relationships to Child Eating and Weight Status. Obesity Research, 12(11), 1711-1722. https://doi.org/10.1038/oby.2004.212

Faith, M. S., Pietrobelli, A., Heo, M., Johnson, S. L., Keller, K. L., Heymsfield, S. B., \& Allison, D. B. (2012). A twin study of self-regulatory eating in early childhood: Estimates of genetic and environmental influence, and measurement considerations. International Journal of Obesity, 36(7), 931-937. https://doi. org/10.1038/ijo.2011.258

Fisher, J. O., \& Birch, L. L. (1999). Restricting access to palatable foods affects children's behavioral response, food selection, and intake. The American Journal of Clinical Nutrition, 69(6), $1264-1272$.

Fisher, J. O., \& Birch, L. L. (2002). Eating in the absence of hunger and overweight in girls from 5 to $7 \mathrm{y}$ of age. The American Journal of Clinical Nutrition, 76(1), 226-231.

Frankel, L. A., Hughes, S. O., O'Connor, T. M., Power, T. G., Fisher, J. O., \& Hazen, N. L. (2012). Parental influences on children's self-regulation of energy intake: Insights from developmental literature on emotion regulation. Journal of Obesity, 2012, 1-12. https://doi.org/10.1155/2012/327259

Frankel, L. A., O'Connor, T. M., Chen, T. A., Nicklas, T., Power, T. G., \& Hughes, S. O. (2014). Parents' perceptions of preschool children's ability to regulate eating. Feeding style differences. Appetite, 76, 166-174.

Freisthler, B., Gruenewald, P. J., Tebben, E., Shockley McCarthy, K., \& Price Wolf, J. (2021). Understanding at-the-moment stress for parents during COVID-19 stay-at-home restrictions. Social Science \& Medicine, 279, 114025. https://doi.org/10.1016/j.socsc imed.2021.114025

Gelman, A., \& Hill, J. (2006). Data analysis using regression and multilevel/hierarchical models. Cambridge University Press.

George, D., \& Mallery, P. (2003). SPSS for Windows step by step: A simple guide and reference 11.0 update (4th ed.). Allyn \& Bacon.

Gouveia, M. J., Canavarro, M. C., \& Moreira, H. (2019). How can mindful parenting be related to emotional eating and overeating in childhood and adolescence? The mediating role of parenting stress and parental child-feeding practices. Appetite, 138, 102-114.

Gruber, J., Prinstein, M. J., Clark, L. A., Rottenberg, J., Abramowitz, J. S., Albano, A. M., Aldao, A., Borelli, J. L., Chung, T., Davila, J., Forbes, E. E., Gee, D. G., Hall, G. C. N., Hallion, L. S., Hinshaw, S. P., Hofmann, S. G., Hollon, S. D., Joormann, J., Kazdin, A. E., ... Weinstock, L. M. (2021). Mental health and clinical psychological science in the time of COVID-19: Challenges, opportunities, and a call to action. The American Psychologist, 76(3), 409-426. https://doi.org/10.1037/amp0000707
Hair, J. F., Black, W. C., Babin, B. J., \& Anderson, R. E. (2010). Multivariate data analysis: A global perspective (7th ed.). Pearson Education.

Hiraoka, D., \& Tomoda, A. (2020). Relationship between parenting stress and school closures due to the COVID-19 pandemic. Psychiatry and Clinical Neurosciences, 74(9), 497-498. https://doi. org/10.1111/pen.13088

Hughes, S. O., Power, T. G., Liu, Y., Sharp, C., \& Nicklas, T. A. (2015). Parent emotional distress and feeding styles in low-income families. The role of parent depression and parenting stress. Appetite, 92, 337-342.

Hurley, K. M., Black, M. M., Papas, M. A., \& Caufield, L. E. (2008). Maternal Symptoms of Stress, Depression, and Anxiety Are Related to Nonresponsive Feeding Styles in a Statewide Sample of WIC Participants. The Journal of Nutrition, 138(4), 799-805. https://doi.org/10.1093/jn/138.4.799

Hurley, K. M., Cross, M. B., \& Hughes, S. O. (2011). A systematic review of responsive feeding and child obesity in high-income countries. The Journal of Nutrition, 141(3), 495-501.

Jansen, E., Mallan, K. M., Nicholson, J. M., \& Daniels, L. A. (2014). The feeding practices and structure questionnaire: Construction and initial validation in a sample of Australian first-time mothers and their 2-year olds. International Journal of Behavioral Nutrition and Physical Activity, 11(1), 72. https://doi.org/10.1186/ 1479-5868-11-72

Johnson, S. L., \& Birch, L. L. (1994). Parents' and Children's Adiposity and Eating Style. Pediatrics, 94(5), 653. http://pediatrics.aappu blications.org/content/94/5/653.abstract

Kroenke, K., Spitzer, R. L., Williams, J. B. W., \& Löwe, B. (2009). An Ultra-Brief Screening Scale for Anxiety and Depression: The PHQ-4. Psychosomatics, 50(6), 613-621. https://doi.org/10.1016/ S0033-3182(09)70864-3

Lee, S. J., Ward, K. P., Chang, O. D., \& Downing, K. M. (2021). Parenting activities and the transition to home-based education during the COVID-19 pandemic. Children and Youth Services Review, 122, 105585. https://doi.org/10.1016/j.childyouth.2020. 105585

Lindsay, A. C., Mesa, T., Greaney, M. L., Wallington, S. F., \& Wright, J. A. (2017). Associations Between Maternal Depressive Symptoms and Nonresponsive Feeding Styles and Practices in Mothers of Young Children: A Systematic Review. JMIR Public Health and Surveillance, 3(2), e29-e29. https://doi.org/10.2196/publi chealth.6492

Marchetti, D., Fontanesi, L., Mazza, C., Di Giandomenico, S., Roma, P., \& Verrocchio, M. C. (2020). Parenting-Related Exhaustion During the Italian COVID-19 Lockdown. Journal of Pediatric Psychology, 45(10), 1114-1123. https://doi.org/10.1093/jpepsy/ jsaa093

Marteau, T. M., \& Bekker, H. (1992). The development of a six-item short-form of the state scale of the Spielberger State-Trait Anxiety Inventory (STAI). British Journal of Clinical Psychology, 31(3), 301-306.

McLean, C. P., \& Anderson, E. R. (2009). Brave men and timid women? A review of the gender differences in fear and anxiety. Clinical Psychology Review, 29(6), 496-505.

Mundfrom, D. J., Perrett, J. J., Schaffer, J., Piccone, A., \& Roozeboom, M. (2006). Bonferroni adjustments in tests for regression coefficients. Multiple Linear Regression Viewpoints, 32, 1-6.

Muthén, L. K., \& Muthén, B. O. (1998-2017). Mplus user's guide (8th ed.). Muthén \& Muthén.

Neece, C. L., Green, S. A., \& Baker, B. L. (2012). Parenting Stress and Child Behavior Problems: A Transactional Relationship Across Time. American Journal on Intellectual and Developmental Disabilities, 117(1), 48-66. https://doi.org/10.1352/1944-7558-117.1. 48 
östberg, M. (1998). Parental stress, psychosocial problems and responsiveness in help-seeking parents with small (2-45 months old) children. Acta Paediatrica, 87(1), 69-76. https://doi.org/10. 1111/j.1651-2227.1998.tb01389.x

Petts, R. J., Carlson, D. L., \& Pepin, J. R. (2020). A gendered pandemic: Childcare, homeschooling, and parents' employment during COVID-19. Gender, Work \& Organization, 28, $515-534$.

Prime, H., Wade, M., \& Browne, D. T. (2020). Risk and resilience in family well-being during the COVID-19 pandemic. American Psychologist, 75(5), 631.

Rollè, L., Prino, L. E., Sechi, C., Vismara, L., Neri, E., Polizzi, C., Trovato, A., Volpi, B., Molgora, S., Fenaroli, V., Ierardi, E., Ferro, V., Lucarelli, L., Agostini, F., Tambelli, R., Saita, E., Riva Crugnola, C., \& Brustia, P. (2017). Parenting stress, mental health, dyadic adjustment: A structural equation model. Frontiers in Psychology, 8, 839. https://doi.org/10.3389/fpsyg.2017.00839

Salari, N., Hosseinian-Far, A., Jalali, R., Vaisi-Raygani, A., Rasoulpoor, S., Mohammadi, M., Rasoulpoor, S., \& Khaledi-Paveh, B. (2020). Prevalence of stress, anxiety, depression among the general population during the COVID-19 pandemic: A systematic review and meta-analysis. Globalization and Health, 16(1), 1-11.

Smith, K. R., Jansen, E., Thapaliya, G., Aghababian, A. H., Chen, L., Sadler, J. R., \& Carnell, S. (2021). The influence of COVID19-related stress on food motivation. Appetite, 163, 105233.

Tan, C. C., \& Holub, S. C. (2011). Children's self-regulation in eating: Associations with inhibitory control and parents' feeding behavior. Journal of Pediatric Psychology, 36(3), 340-345. https://doi. org/10.1093/jpepsy/jsq089

Vohs, K. D., \& Baumeister, R. F. (Eds.). (2016). Handbook of self-regulation: Research, theory, and applications. Guilford Publications.

Yoshikawa, H., Wuermli, A. J., Britto, P. R., Dreyer, B., Leckman, J. F., Lye, S. J., Ponguta, L. A., Richter, L. M., \& Stein, A. (2020). Effects of the Global Coronavirus Disease-2019 Pandemic on Early Childhood Development: Short- and Long-Term Risks and Mitigating Program and Policy Actions. The Journal of Pediatrics, 223, 188-193. https://doi.org/10.1016/j.jpeds.2020.05.020

Publisher's Note Springer Nature remains neutral with regard to jurisdictional claims in published maps and institutional affiliations. 